\title{
Tratamento Medicamentoso dos Tumores Hipofisários. Parte I: Prolactinomas e Adenomas Secretores de GH
}

\section{RESUMO}

O recente desenvolvimento de novas drogas, particularmente os análogos da somatotastina (SRIFa), representou um grande progresso na terapia dos tumores hipofisários. Os SRIFa mostram-se bastante eficazes na normalização dos niveis de GH e IGF-1 em acromegálicos e podem ser uma alternativa para a cirurgia transesfenoidal, mas seu uso como terapia primária da acromegalia fica limitado pelo pequeno efeito dessas drogas na redução das dimensões do tumor. Os resultados preliminares com os antagonistas do receptor de $\mathrm{GH}$, como o pegvisomant, são bastante animadores. Tais drogas permitem a normalização do IGF-1 e meIhora clínica em mais de $80 \%$ dos casos; entretanto, não causam redução tumoral. Agonistas dopaminérgicos $(D A)$ representam a terapia de escolha para microprolactinomas sintomáticos e macroprolactinomas, permitindo normalização dos niveis da prolactina e redução do volume do adenoma na maioria dos pacientes. Podem também ser eventualmente eficazes em acromegálicos, sobretudo naqueles com adenomas co-secretores de prolactina e níveis não muito elevados de $\mathrm{GH}$ e IGF-1. Devido a sua maior eficácia e melhor tolerabilidade, a cabergolina representa o DA de escolha para o manuseio dos prolactinomas e da acromegalia. (Arq Bras Endocrinol Metab 2000;44/5: 367-381)

Unitermos: Adenomas hipofisários; Tratamento; Análogos da somatostatina: Agonistas dopaminérgicos; Antagonistas do receptor do $\mathrm{GH}$.

\begin{abstract}
The recent development of new drugs, particularly the somatostatin analogues (SRIFa), represents a great advance in the therapy of pituitary tumours. SRIFas are very effective in normalizing GH and IGF-1 levels in acromegaly and may be an effective alternative to transsphenoidal surgery. However, their usefuiness as primary therapy for acromegaly is limited due to the small effect on tumour size. According to early data from clinical trials, pegvisomant, a $\mathrm{GH}$ receptor antagonist, seems to be a promising therapeutic tool in the management of acromegalic patients. This drug induces significant clinical improvement and normalization of IGF-1 levels in nearly all patients. However, it does not induce tumor shrinkage. Dopamine agonists (DA) are the preferred therapy for both symptomatic microprolactinomas and macroprolactinomas; their use result in normalization of prolactin levels and tumor shrinkage in most treated patients. They also may be useful in acromegaly, mainly in patients whose adenoma co-secrete prolactin and those with mild elevation of $\mathrm{GH}$ and IGF-1 levels. Due to its greater effectiveness and better tolerability, cabergoline represents the DA of choice for the management of prolactinomas and acromegaly. (Arq Bras Endocrinol Metab 2000;44/5: 367-381)
\end{abstract}

Keywords: Pituitary Adenomas; Treatment; Somatostatin analogues; Dopamine agonists; $G H$ receptor antagonists.

\section{revisão}

\author{
Lucio Vilar \\ Luciana Naves \\ Maria da Conceição Freitas \\ Sebastião Oliveira Jr \\ Verônica Leite \\ Viviane Canadas
}

Disciplina de Endocrinologia da Universidade Federal de

Pernambuco ( $L V, V L, V C)$.

Disciplina de Endocrinologia da

Universidade de Brasilia (LN),

Unidade de Endocrinologia do

Hospital Getúlio Vargas (MCF) e

Disciplina de Endocrinologia da Universidade de Pernambuco (SOJr)

Recebido em: 21/05/99

Revisado em: 13/01/00 e 06/08/00

Aceito em: $20 / 08 / 00$ 
$\mathrm{O}$ S ADENOMAS HIPOFISÁRIOS REPRESENTAM 10-15\% dos tumores intracranianos em amostras cirúrgicas e $6-23 \%$ desses tumores em séries não selecionadas de autópsias em adultos (1). São também detectados em $10 \%$ da população adulta em estudos de imagem por tomografia computadorizada (2) e ressônancia magnética (3). Entretanto, seu reconhecimento clínico é muito mais raro, com prevalência de 200 casos por milhão e incidência anual de 15 novos casos por milhão (4). Na tabela 1 está discriminada a freqüência relativa dos adenomas hipofisários entre 1.043 casos (1). Esses tumores são habitualmemente classificados como micro ou macroadenomas, se tiverem, respectivamente, menos ou mais de $1 \mathrm{~cm} \mathrm{(4).}$

As metas do tratamento dos adenomas hipofisários incluem a reversão da hipersecreção hormonal e suas manifestações clínicas, bem como a regressão de uma eventual sintomatologia neurológica ou neuro-ocular provocada pela compressão tumoral sobre o quiasma óptico e outras estruturas para-selares (5). A função residual da hipófise anterior deve ser preservada ou, se previamente comprometida, restaurada (5). Além disso, deve-se procurar prevenir uma posterior recidiva tumoral (5).

Classicamente, a cirurgia tem sido considerada a opção terapêutica de escolha para os tumores hipofisários, enquanto a radioterapia e as drogas são utilizadas como coadjuvantes (5-7). As únicas exceções são os prolactinomas para os quais os agonistas dopaminérgicos são considerados a terapia mais eficaz (7). Na última década, com o advento de novas drogas, passou-se a atribuir um papel mais relevante ao tratamento medicamentoso para os demais tipos de adenomas hipofisários, inclusive como terapia primária (8-14).

Na presente revisão - a primeira de duas partes, avaliamos a eficácia da abordagem farmacológica em pacientes com adenomas hipofisários secretores de prolactina e secretores de $\mathrm{GH}$, comparando-a aos resultados obtidos com a cirurgia e/ou radioterapia e comentamos sobre sua relevância no tratamento desses

Tabela 1. Freqüência relativa dos adenomas hipofisários entre 1.043 casos (modificado da ref. 1)

\begin{tabular}{lr} 
Prolactinomas & $27,2 \%$ \\
Não-secretores & $25,2 \%$ \\
Secretores de GH & $14,0 \%$ \\
Secretores de GH + PRL & $8,0 \%$ \\
Secretores de ACTH & $14,0 \%$ \\
Secretores de gonadotrofinas & $6,4 \%$ \\
Secretores de TSH & $1,0 \%$ \\
Pluri-hormonais & $3,7 \%$ \\
\hline
\end{tabular}

Tabela 2. Agonistas dopaminérgicos

\begin{tabular}{|c|c|c|}
\hline Droga & Nome comercial & Dose usual \\
\hline Bromocriptina & \multicolumn{2}{|c|}{ Parlodek ${ }^{\circledR}$, Bagren $\AA 2,5 \mathrm{mg}, 2-3 x$ dia } \\
\hline & Parlodel SROB & $5,0-7,5 \mathrm{mg}, 1 \times$ dia \\
\hline Lisurida & Dopergin $\oplus$ & $0,2 \mathrm{mg}, 2-3 \mathrm{x}$ dia \\
\hline Pergolida * & Permax® & $0,05-2 \mathrm{mg}, 1-2 \mathrm{x}$ dia \\
\hline Cabergolina & Dostinex( & $0,5-1 \mathrm{mg}, 1-2 x$ semana \\
\hline Quinagolida * & Norprolac ${ }^{\circledR}$ & $0,075-0,25 \mathrm{mg}, 1 \times \mathrm{dia}$ \\
\hline
\end{tabular}

Prolactinomas são os tumores hipofisários secretores mais comuns (até $60 \%$ dos casos) e predominam no sexo feminino $(5,15,16)$. Cerca de $95 \%$ são microadenomas, mas entre homens predominam os macros $(80-90 \%$ dos casos) $(15,16)$. Microprolactinomas não tendem a crescer com o tempo, sendo excepcional sua progressão para macroprolactinomas (risco inferior a 7\%) (17). Além disso, estudos sobre a história natural dos microprolactinomas mostraram que, em aproximadamente um terço dos casos sem tratamento, pode haver melhora dos sintomas, desaparecimento da galactorréia e/ou normalização da prolactina (PRL) (18-20). Por essas razões, recomenda-se que pacientes albergando um microprolactinoma sejam tratados apenas se cursarem com distúrbios gonadais (amenorréia, infertilidade), disfunção sexual (diminuição da libido, disfunção erétil), osteoporose prematura, galactorréia muito incômoda ou crescimento tumoral durante o seguimento $(17,21)$.

O principal diagnóstico diferencial dos macroprolactinomas é com os pseudoprolactinomas (PP), representados, sobretudo, pelos adenomas clínicamente não funcionantes, que causam hiperprolactinemia por compressão da haste hipofisária (15). Os níveis de PRL em pacientes com PP geralmente são $<100$ $\mathrm{ng} / \mathrm{mL}$ e quase nunca excedem $250 \mathrm{ng} / \mathrm{mL}$ (15). Em contraste, usualmente superam $200 \mathrm{ng} / \mathrm{mL}$ nos casos de macroprolactinomas (17). Em pacientes com micropolactinoma, a prolactinemia, em geral, situa-se entre 100 e $200 \mathrm{ng} / \mathrm{mL}$, mas não raramente encontrase abaixo de $100 \mathrm{ng} / \mathrm{mL}$ (15).

Desde o surgimento da bromocriptina, agonista dopaminérgico derivado do ergot, há 28 anos (22), a terapia medicamentosa vem sendo considerada a melhor forma de tratar os prolactinomas $(5,7,21)$. Como alternativa, temos a cirurgia e a radioterapia hipofisária.

* ainda não comercializados no Brasil

tumores. Na parte 2 (a ser publicada em seguida), será
abordado o tratamento dos adenomas produtores de $\mathrm{ACTH}, \mathrm{TSH}$ e aqueles clinicamente não-funcionantes.

\section{PROLACTINOMAS}




\section{Agonistas Dopaminérgicos}

Atuam diretamente ao nível dos receptores $D_{2}$ da dopamina nas células lactotróficas normais e adenomatosas, inibindo a síntese e a liberação de prolactina e diminuindo a atividade neuronal dopaminérgica (16). Dentre os compostos disponiveis, bromocriptina, lisurida e, mais recentemente, cabergolina são comercializadas em nosso meio.

1. Bromocriptina (BRC) - Classicamente tem sido considerada a droga de escolha no tratamento dos prolactinomas $(5,7,15)$. Está disponivel na forma de comprimidos (2,5 e $5 \mathrm{mg}$ ) e cápsulas de liberação lenta ( $S R O$ - slow release oral, 2,5 e $5 \mathrm{mg}$ ). Estas últimas apresentam a vantagem de poderem ser administradas em dose única diária, enquanto os comprimidos requerem habitualmente duas a três tomadas/dia; usualmente, são também melhor toleradas $(15,23,24)$. Recomendase iniciar com $1,25 \mathrm{mg}$, à noite, à hora de deitar, juntamente com uma pequena refeição (para retardar a absorção) e aumentar a dose gradativamente, de acordo com a tolerância individual, até ser atingida a resposta terapêutica $(7,15,16)$. A dose usual da BRC é de $5-7,5 \mathrm{mg} /$ dia; doses maiores que $7,5 \mathrm{mg} /$ dia geralmente não são necessárias, exceto na presença de grandes tumores $(7,17)$. A maioria dos pacientes que respondem à droga, o farão dentro de 1 a 2 meses (17).

Existe também uma forma injetável de bromocriptina, de ação prolongada (Parlodel LAR ${ }^{\circledR}$, Sandoz, Basiléia), para aplicação intramuscular profunda (50-150 mg), a intervalos de 4 semanas (25). Essa apresentação, não comercializada em nosso meio, tem tolerabilidade e eficácia similares a BRC oral (26).

Eficácia clínica. Em uma revisão de vários grandes estudos, totalizando mais de 400 pacientes tratados com BRC, observou-se normalização da PRL em 70-80\% das pacientes e retorno de menstruações ovulatórias em 80-90\% $(27,28)$. Em 236 casos de macroprolactinomas, significativa redução tumoral foi observada em $77 \%$ (27). Na maioria dos pacientes, essa redução ocorre dentro de dois meses do início do tratamento, mas pode acontecer somente após seis meses $(29,30)$.

Tabela 3. Efeitos colaterais dos agonistas dopaminérgicos em pacientes com hiperprolactinemia

\begin{tabular}{ll}
\hline COMuns & RAROS \\
- Náuseas, vômitos & - Depressão \\
- Tonturas & - Psicose \\
- Cefaléia & - Rinoliquorréia \\
- Fadiga & \\
- Congestão nasal & \\
- Hipotensão postural & \\
- Constipação, dor abdominal & \\
- Espasmo digital induzido pelo frio \\
\hline
\end{tabular}

De acordo com a literatura, $5-18 \%$ dos prolactinomas têm resistência a $B R C(31,32)$, definida como a falta de normalização dos níveis de PRL e/ou redução tumoral após 3 meses de tratamento com uma dose de BRC $>15 \mathrm{mg} /$ dia (15). Tal fenômeno resultaria de uma reduzida densidade dos receptores dopaminérgicos do tipo $D_{2}$ nas células tumorais, mas adicionalmente poderia haver defeito pós-receptor $(16,32)$. Havendo resistência tumoral a BRC, a cirurgia pode vir a ser necesssária (15). Deve-se, contudo, tentar antes uma outra droga. Neste contexto, a cabergolina e a quinagolida são as mais eficazes (ver abaixo), por serem mais potentes e apresentarem maior seletividade para os receptores dopaminérgicos $D_{2}$, em comparação aos demais agonistas $(15,31,33)$.

É importante salientar que para a paciente cujo tratamento com BRC não normalize a PRL, mas permite níveis estrogênicos suficientes para fazê-la menstruar regularmente, pelo menos, a cada dois meses, a troca por um outro agonista dopaminérgico ou a opção pela cirurgia não são obrigatórias $(15,16,21)$. Entretanto, se o problema principal for infertilidade persistente a despeito da redução da PRL, normalização da prolactinemia deve ser tentada (15).

Os efeitos colaterais da BRC são comuns aos demais agonistas dopaminérgicos e acometem até $80 \%$ dos pacientes $(34,35)$. Tendem a ser mais acentuados com doses diárias $>7,5 \mathrm{mg} /$ dia, administração da medicação sem aumentos graduais da dose ou com o paciente em jejum, ou ainda, pela ingestão concomitante de bebidas alcoólicas $(7,15,21,34)$. Entre as manifestações mais comuns temos náuseas (50\%), cefaléia (29\%), tonturas (26\%) e fadiga (18\%) (36). Reações psicóticas foram observadas em 8 de 600 $(1,3 \%)$ pacientes que receberam BRC ou lisurida para o tratamento de hiperprolactinemia ou acromegalia (37). Raramente, a rápida redução tumoral induzida pela BRC pode resultar no surgimento de rinoliquorréia $(16,38)$. As reações adversas a $B R C$ são geralmente leves e transitórias. No entanto, 5 a $10 \%$ dos pacientes são forçados a interromper o tratamento, em decorrência, sobretudo, de sintomas intensos ou persistentes de náuseas, vômitos, tonturas e/ou hipotensão postural $(5,17,21)$. Raramente, congestão nasal persistente pode ser a causa da suspensão da medicação (16). Em caso de surgimento de efeitos colaterais importantes que impeçam a continuação do tratamento, deve-se substituir a BRC por um outro agonista dopaminérgico (15,31). Resultados satisfatórios também foram relatados com a bromocriptina injetável $(21,27)$, assim como pelo uso intravaginal de comprimidos de BRC (39) ou cabergolina (40). 
2. Lisurida - Tem eficácia similar a BRC, mas na nossa experiência (31) e na de outros autores (41), causa mais efeitos colaterais. Contudo, um estudo alemão com 27 pacientes mostrou que ambas as drogas foram igualmente eficazes e bem toleradas (42). Ocasionalmente, pacientes intolerantes ou resistentes a BRC podem responder a lisurida (31).

3. Quinagolida - Único agonista não derivado do ergot, em comparação a BRC apresenta eficácia similar, melhor tolerabilidade e, como mencionado, maior seletividade pelos receptores $\mathrm{D}_{2}$ (43-45). Por isso, em pacientes intolerantes e resistentes a BRC, propiciou normalização da PRL em, respectivamente, $67 \%$ e $35 \%$ dos casos (31). Deve-se iniciar o tratamento com um comprimido de $75 \mu \mathrm{g} /$ dia e a maioria dos pacientes têm resposta satisfatória com dose única diária de até $225 \mu \mathrm{g}$. No caso de resistência a BRC, doses de até $600 \mu \mathrm{g} /$ dia podem ser necessárias (31).

4. Cabergolina - Apresenta uma duração de ação de até 21 dias após uma dose única oral de 0,3 a $1 \mathrm{mg}$ (46). Assim, tem a grande vantagem de poder ser administrada apenas 1 a 2 vezes por semana (47), enquanto os demais agonistas requerem uma a três tomadas diárias (15). Está disponível em comprimidos de $0,5 \mathrm{mg}$. Recomenda-se iniciar o tratamento com $0,25 \mathrm{mg}$, uma a duas vezes por semana, com reajustes semanais da dose, até atingir $1 \mathrm{mg}$ semanal (em duas tomadas) $(15,36,47)$. Essa posologia é suficiente para normalizar os níveis de prolactina na maioria dos pacientes $(15,47)$. Não raramente, pode ser reduzida para 0,25-0,5 mg/semana, uma vez que o controle da hiperprolactinemia tenha sido alcançado (48). Entre 455 pacientes, a dose média satisfatória foi de 1 $\mathrm{mg} /$ semana (variação de $0,5-3 \mathrm{mg}$ ) para macroprolactinomas e 0,5 mg/semana (variação de 0,25-1 mg) para microprolactinomas e hiperprolactinemia idiopática (48). Pacientes com resistência a BRC podem requerer doses tão altas quanto $0,5 \mathrm{mg} /$ dia para normalizarem a PRL (15), mas a maioria responde a doses de até $3 \mathrm{mg} /$ semana $(33,48)$.

Eficácia clínica - O uso da cabergolina (CAB) possibilitou a normalização da PRL em $83-96 \%$ dos pacientes com microprolactinoma (48-50) e em 73$100 \%$ daqueles com macroadenoma $(36,48,51,52)$. Resultou também em significante redução do tamanho de $38-92 \%$ dos macroprolactinomas, com desaparecimento da imagem tumoral à ressonância magnética em 13-61\% $(51,52)$. A eficácia da $C A B$ em reduzir as dimensões tumorais pode ser maior em pacientes virgens de tratamento do que naqueles previamente tratados com outros agonistas dopaminér- gicos, conforme sugerido por um recente estudo italiano (52). Quando comparada a BRC, a CAB apresentou melhor tolerabilidade e maior eficácia em normalizar a PRL $(33,53)$. Em um estudo duplo-cego, envolvendo mulheres com amenorréia hiperprolactinêmica, normalização da PRL e taxa de abandono da terapia foram, respectivamente, de 59 e $3 \%$ com a $\mathrm{CAB}$, e 33 e $12 \%$ com a BRC (53). Foi também relatado que, em comparação a $\mathrm{BRC}, \mathrm{CAB}$ induziu melhora mais precoce da disfunção gonadal e sexual em homens hiperprolactinêmicos (54).

Em casos de resistência a $B R C$, a utilização da CAB propiciou normalização da PRL em $51-85 \%$ dos pacientes $(33,48,52,55)$ e resultou em significante redução tumoral em 30-66\% dos macroprolactinomas $(33,51,52,56)$ e em $50 \%$ dos microprolactinomas (33). Normalização da prolactinemia foi também observada em 84-100\% dos pacientes com intolerância a $B R C$. $(33,48,52,55)$. Na nossa casuística, observamos níveis normais da PRL em 8/10 (80\%) pacientes intolerantes a BRC e em 3/5 (60\%) resistentes (57). Uma paciente intolerante voltou a menstruar, a despeito da não normalização da PRL.

Os efeitos colaterais da $\mathrm{CAB}$ são os mesmos observados com a BRC, mas com freqüencia significativamente menor $(33,47,48,53)$. Intolerância a CAB foi relatada em apenas 3 a $4 \%$ dos pacientes $(48,49,52,53,56)$.

\section{Duração do tratamento com os agonistas dopaminérgicos (DAs)}

Uma vez suspenso o tratamento com os DAs, habitualmente observa-se recidiva da hiperprolactinemia que pode ou não se acompanhar de reexpansão tumoral (58). No entanto, persistência de níveis normais de prolactina foi relatada em 10 a $25 \%$ dos pacientes (sobretudo naqueles com microprolactinoma) após a suspensão do tratamento prolongado com BRC $(15,16,58-60)$ ou cabergolina (61). Tem-se, por isso, recomendado a suspensão do tratamento com o DA a cada 12 a 24 meses para avaliar se a hiperprolactinemia persistirá ou não $(15,58)$. No caso de grandes adenomas responsivos a BRC, a suspensão deve ser gradual, devendo-se interrompê-la caso ocorra aumento nos níveis da PRL ou nas dimensões tumorais (17).

\section{Uso de DAs durante a gestaçāo}

Confirmada a gravidez, o DA deverá ser suspenso de imediato. Quando usada dessa maneira, em cerca de 6.000 gestações, a $\mathrm{BRC}$ não se associou a nenhum aumento na ocorrência de abortos espontâneos, 
gravidezes ectópicas ou múltiplas, doença trofoblástica ou malformações congênitas (62). Dados sobre a segurança do uso $B R C$ por toda a gestação são ainda escassos, mas sugerem que essa droga provavelmente seria também segura para uso contínuo durante a gravidez $(17,62,63)$. Também não se constatou uma maior incidência de malformações fetais ou abortos espontâneos em 265 gravidezes de mulheres fazendo uso de cabergolina $(17,63,64)$.

Uma das complicações dos prolactinomas durante a gestação é seu crescimento (risco de 1,6 a $5,5 \%$ para os microadenomas e de 15,5 a $35,7 \%$, com os macros) (62). Caso ocorra expansão tumoral sintomática, deve-se administrar a BRC e mantê-la até o final da gestação (62). Se a resposta for insatisfatória, tentar a cabergolina; cirurgia $(27,62)$ ou, menos freqüentemente, glicocorticóides em altas doses (63) são consideradas alternativas para os casos nãoresponsivos aos DAs. O acompanhamento das pacientes com macrodenomas volumosos deve ser feito com campimetrias mensais, uma vez que os niveis de PRL não representam um bom indicador do crescimento do adenoma $(17,27)$.

\section{Cirurgia}

A cirurgia transesfenoidal é a técnica de escolha para microadenomas e a maioria dos macroadenomas. Craniotomia raramente se faz necessária. Entre 1.224 pacientes com microprolactinoma e 1.256 com macroprolactinoma submetidos à adenomectomia transesfenoidal, cura cirúrgica (definida como normalização dos níveis de PRL) foi observada em 71\% e 32\% dos casos, respectivamente (27). Além disso, recidiva precoce da hiperprolactinemia (dentro do primeiro ano após a cirurgia) acontece em 10 a $15 \%$ dos pacientes (5), enquanto, a longo prazo, a recorrência pode chegar a $31 \%$ para os micros e $91 \%$ para os macroprolactinomas (31), com uma média de aproximadamente $18 \%$ para ambos $(17,27)$. O percentual de cura cirúrgica definitiva seria de $50-60 \%$ para micros e de aproximadamente $25 \%$ para os macroprolactinomas (17).

As complicações da cirurgia transesfenoidal não são freqüentes, mas sua ocorrência depende da experiência e habilidade do neurocirurgião, bem como do tamanho do tumor (mais comuns com macroadenomas) $(34,35,65)$. Entre elas se incluem hipopituitarismo (deficiência de ACTH em 2-67\%, TSH em 3-51\% e gonadotrofinas em 3-58\%), diabetes insipidus (DI) permanente (1-9\%), perda da visão $(0,1-1,5 \%)$, paralisia oculomotora $(0,1-0,6 \%)$, meningite $(0,1-0,5 \%)$, abscesso $(<1 \%)$, hematoma $(<1 \%)$, rinoliquorréia $(1,3-3,3 \%)$ e acidente vascular cerebral ou lesão vascular $(0,2$ a $0,6 \%)$
$(34,35,65)$. DI transitório ocorre em cerca de $30 \%$ dos pacientes (66). A taxa de mortalidade cirúrgica é muito baixa, sendo geralmente inferior a $0,5 \%$ e $1 \%$ para micros e macroadenomas, respectivamente (17). O risco dessas complicações aumenta significativamente em caso de cirurgia ou radioterapia prévias $(65,66)$.

Devido aos resultados satisfatórios geralmente obtidos com os agonistas dopaminérgicos, costuma-se reservar a indicação cirúrgica para situações especiais, tais como: a) intolerância ou resistência às drogas; b) complicações do tumor: hemorragia ou rinoliquorréia; c) ausência de resposta imediata à terapia medicamentosa em pacientes com macroadenomas invasivos que comprometam a visão; d) opção do paciente $(5,15)$. Mais recentemente, alguns serviços voltaram a preconizar a cirurgia para os microprolactinomas, referindo cura definitiva em até $84 \%$ dos casos (melhores resultados com níveis de prolactina $\leq 100$ $\mathrm{ng} / \mathrm{mL}$ ) (67). Resultados brilhantes assim somente são conseguidos, todavia, por um número muito limitado de neurocirurgiões no mundo todo (7).

\section{Radioterapia}

Com a radioterapia hipofisária externa convencional, na dose total de 4.500 cGy, observou-se normalização da PRL em 0 a $38 \%$ dos pacientes $(15,17,27,34,35)$. Em estudo mais recente, a prolactinemia normalizouse em cerca de $30 \%$ de 63 pacientes não curados pela cirurgia, após 10 anos (68). Em geral, são necessários 2 a 15 anos para que se obtenha eficácia máxima da radioterapia convencional em prolactinomas $(17,34)$. Os dados com a radiocirurgia gamma-knife - que permite liberar, com acurácia milimétrica e de uma só vez, dosess maiores de radiação para o núcleo do tumor, com menor agressão sobre o hipotálamo, quiasma óptico e cérebro - são ainda limitados (69). Em três estudos, totalizando 16 pacientes, não houve normalização dos níveis de PRL, mas redução dos mesmos aconteceu na maioria dos casos (69-71). A radioterapia deve ser reservada para prolactinomas (sobretudo, os invasivos) sem resposta adequada às outras formas de tratamento (16).

\section{Novas Perspectivas Terapêuticas}

Em pacientes com prolactinoma, somatostatina e octreotida, que se ligam preferencialmente aos receptores somatostatínicos tipo 2, não modificam a secreção da PRL in vivo (5). No entanto, foi demonstrado supressão da secreção de PRL, em culturas de lactotrófos humanos, através do uso de novos análogos somatostínicos com especificidade para o receptor somatostatínico tipo $5(72)$. 


\section{Comentários}

Os agonistas dopaminérgicos representam a opção terapêutica mais eficaz e segura, tanto para micro, como para macroprolactinomas. Por sua maior eficácia, melhor tolerabilidade e maior comodidade posológica em comparação aos demais agonistas dopaminérgicos, a cabergolina representa a droga de escolha. No entanto, como ainda existe maior experiência com o uso da $\mathrm{BRC}$ em grávidas, essa droga poderia ser preferível a $\mathrm{CAB}$ em pacientes cuja queixa principal seja a infertilidade. $\mathrm{CAB}$ constitui também a opção mais eficaz para os casos de resistência ou intolerância a BRC. Análogos somatostínicos com especificidade para o receptor somatostatínico tipo 5 poderão vir a ser úteis no tratamento dos prolactinomas não-responsivos aos agonistas dopaminérgicos.

\section{ADENOMAS SECRETORES DE GH}

Os adenomas hipofisários secretores de $\mathrm{GH}$ são responsáveis por 95\% dos casos de acromegalia, e por $10-15 \%$ de todos os tumores hipofisários (73). A acromegalia é uma doença rara, com incidência anual de 3-4 casos/milhão $(74,75)$ e prevalência estimada de 40 casos/milhão, mas que pode ser tão alta quanto 90 casos/milhão (76). A importância maior do diagnóstico e tratamento precoces dessa doença reside no fato de que, em comparação à população geral, os acromegálicos apresentam uma menor expectativa de vida e uma mortalidade duas a três vezes maior $(75,76)$. Essa excessiva mortalidade, conseqüente às complicações cardiovasculares, respiratórias e neoplásicas da acromegalia, parece poder ser revertida pela obtenção de níveis séricos de GH pós-tratamento $<2,5$ $\mathrm{ng} / \mathrm{mL}(79,80)$

Entre os critérios de "cura" propostos para a acromegalia os mais utilizados têm sido: a) valores de $\mathrm{GH}<2,0 \mathrm{ng} / \mathrm{mL}$, dosados por RIE - ou $<1 \mathrm{ng} / \mathrm{mL}$, através de ensaio imunorradiométrico ou quimioluminescência - dentro de 2 horas após um teste de sobre-

Tabela 4. Percentual de cura ( $\mathrm{GH}$ médio $<2,5 \mathrm{ng} / \mathrm{ml}$ ) em 100 acromegálicos submetidos à cirurgia transesfenoidal (modificado da ref. 82)

\begin{tabular}{cc}
\hline & Cura (\%) \\
\hline - De acordo com niveis pré-operatórios de $\mathrm{GH}$ & \\
$<10 \mathrm{ng} / \mathrm{ml}$ & 65 \\
$10-50 \mathrm{ng} / \mathrm{ml}$ & 43 \\
$>50 \mathrm{ng} / \mathrm{ml}$ & 20 \\
- De acordo com o tamanho do tumor & \\
Microadenomas & 61 \\
Macroadenomas & 23 \\
Micro + macros & 42 \\
\hline
\end{tabular}

carga oral com $75 \mathrm{~g}$ de glicose (OGTT) + normalização do IGF-1 (81); b) níveis médios de GH (4-5 dosagens diárias) $<2,5 \mathrm{ng} / \mathrm{mL}(\mathrm{RIE})+$ normalização do IGF-1 (82). Em um recente consenso, foi proposto um nadir do $\mathrm{GH}<1 \mathrm{mg} / \mathrm{L}$ durante o OGTT e niveis normais de IGF, tanto para exluir acromegalia quanto para definição de cura (84). Uma concentração de $\mathrm{GH}$ ao acaso $<0,4 \mu \mathrm{g} / \mathrm{L}$, associada a valores normais de IGF-1, também excluiria acromegalia. Neste consenso foi também antecipado que valores de cut-off mais baixos poderão vir a ser adotados com surgimento de novos ensaios mais sensiveis para o $\mathrm{GH}$.

Classicamente, a cirurgia por via transesfenoidal é considerada a terapia de escolha para os adenomas secretores de GH $(81,83)$. Outras opções são a radioterapia hipofisária e o tratamento medicamentoso, à base dos análogos somatostatínicos e/ou agonistas dopaminérgicos $(81,83)$.

\section{Cirurgia}

Eficácia clínica - O sucesso da adenomectomia transesfenoidal (TSA) depende da habilidade e experiência do cirurgião, dimensão e grau de invasibilidade do tumor, assim como dos niveis pré-operatórios do GH; os melhores resultados são em pacientes com microadenoma e os piores, naqueles com $\mathrm{GH}>40-50$ $\mathrm{ng} / \mathrm{mL}$ e tumores com extensão supra-selar ou invasão do seio cavernoso $(4,66,82,85-90)$, conforme exemplificado nas tabelas 4 e 5 . Normalização do $\mathrm{GH}$ foi relatada em 40 a $91 \%$ dos microadenomas e 23 a $53 \%$ dos macros $(66,82,87,89,90)$. Na Inglaterra, níveis de $\mathrm{GH}<2,5 \mathrm{ng} / \mathrm{mL}$ são observados com uma freqüência significativamente maior em serviços onde um único neurocirurgião realiza a TSA (90). Normalização do IGF-1 ocorre em $50-75 \%$ dos acromegálicos submetidos à cirurgia transesfenoidal (91). Recidiva da elevação dos níveis de $\mathrm{GH}$, após um seguimento de 8 a 10 anos, varia de 8 a $10 \%$, sendo mais comum com tumores invasivos (66).

\section{Radioterapia}

Eficácia clínica - A radioterapia conventional (45 Gy, divididos em 25 frações diárias de 1,8 Gy) tem como importante limitação o longo tempo necessário para que seu efeito redutor do $\mathrm{GH}$ sérico se manifeste (85,92). Em um estudo recente do Reino Unido, níveis médios de $\mathrm{GH}<2,5 \mathrm{ng} / \mathrm{mL}$ foram observados em $36 \%$ dos pacientes após 2 anos, $44 \%$ após 5 anos, $59 \%$ com 10 anos e $100 \%$ após 20 anos (93). Os resultados também dependem dos niveis de GH pré-tratamento, sendo significativamente melhores nos pacientes com valores $<10 \mathrm{ng} / \mathrm{mL}$ e piores quando 
Tabela 5. Resultados da cirurgia transesfenoidal para a acromegalia, utizando-se critérios de cura mais rigorosos: GH basal médio $<2,5 \mathrm{ng} / \mathrm{ml}$ e/ou $\mathrm{GH}<2 \mathrm{ng} / \mathrm{ml}$ após $75 \mathrm{~g}$ de glicose.

\begin{tabular}{|c|c|c|c|}
\hline Estudo (ref.) & № de pacientes & Tumor & Remissāo (\%) \\
\hline Laws \& Thapar (66) & - & Micro & 72 \\
\hline Sheaves (82) & 100 & $\begin{array}{l}\text { Micro + Macro } \\
\text { Macro } \\
\text { Micro }\end{array}$ & $\begin{array}{l}42 \\
23 \\
61\end{array}$ \\
\hline Post et al (87) & 115 & $\begin{array}{l}\text { Micro + Macro } \\
\text { Micros } \\
\text { Macros } \\
\text { Macro invasivo }\end{array}$ & $\begin{array}{l}61 \\
88 \\
53 \\
42\end{array}$ \\
\hline $\begin{array}{l}\text { Davis et al ( } 88 \text { ) } \\
\text { Jenkins et al ( } 89 \text { ) }\end{array}$ & $\begin{array}{r}175 \\
78\end{array}$ & $\begin{array}{l}\text { Micro + Macro } \\
\text { Micro } \\
\text { Macro } \\
\text { Macro com extensão }\end{array}$ & $\begin{array}{l}52 \\
40 \\
35\end{array}$ \\
\hline Ahmed et al (90) & 139 & $\begin{array}{l}\text { supra-selar } \\
\text { Micro } \\
\text { Macro }\end{array}$ & $\begin{array}{l}25 \\
91 \\
46\end{array}$ \\
\hline
\end{tabular}

$>60 \mathrm{ng} / \mathrm{mL}$ (93). Uma outra limitação da radioterapia seria sua relativa baixa eficácia em normalizar os niveis de IGF-1. Em um estudo com 38 pacientes apenas dois tiveram seu IGF-1 normalizado (94). Entretanto, no mencionado estudo britânico, $56 \%$ dos pacientes apresentavam níveis normais de IGF-1 após 10 anos da radioterapia. O principal inconveniente da radioterapia é o alto risco para o aparecimento de hipopituitarismo. Após 10 anos, observou-se deficiência do $\mathrm{ACTH}$ em $70 \%$, TSH em $48 \%$ e gonadotrofinas em $78 \%$ (93). Curiosamente, deficiência de $\mathrm{GH}$ pode também surgir em acromegálicos submetidos à radioterapia (85). Outras complicações raras são distúrbios visuais (inclusive cegueira) por lesão do nervo óptico, isquemia ou necrose cerebral e carcinogênese cerebral secundária $(35,69)$. Por essas razões, a radioterapia está prioritariamente indicada para os casos em que a cirurgia esteja contra-indicada ou nos pacientes com doença persistente ou recidivante após a cirurgia $(8,81,83)$.

Os limitados dados sobre a radiocirurgia gamma-knife em acromegálicos não têm, de um modo geral, demonstrado uma definitiva superioridade sobre a radioterapia externa convencional (69). Em cinco estudos recentes, envolvendo 59 acromegálicos, a frequeencia de normalização do $\mathrm{GH}$ variou de 30 a $85 \%$ (69-71,95,96). No entanto, há evidências de que o efeito da radiociurgia gamma-knife é significativamente mais rápido. Em estudo recente, $70 \%$ dos pacientes tiveram seu GH normalizado após 16 meses da radiocirurgia enquanto que, com a radioterapia convencional, o mesmo percentual somente foi alcançado após 7 anos (96). Ainda não está claro se as complicações tardias da radiocirurgia seriam menos comuns do que com a radioterapia convencional (69).

\section{Tratamento Medicamentoso}

Como opções principais dispomos dos agonistas dopaminérgicos e análogos da somatostatina $(8,83)$. Estes últimos mostram-se mais eficazes para reduzir os niveis do $\mathrm{GH}$ e do IGF-1, bem como induzir redução tumoral $(8,83)$. No entanto, alguns pacientes responderam melhor quando se associou bromocriptina (BRC) com octreotida (97); além disso, cerca de $10 \%$ dos acromegálicos são refratários a octreotida, mas respondem a BRC $(97,98)$.

De acordo com um consenso sobre benefícios e riscos da terapia medicamentosa na acromegalia, as drogas poderiam ser usadas para os casos de insucesso cirúrgico, contra-indicação para a cirurgia (por ex., pacientes fisicamente enfermos ou com doenças sistêmicas debilitantes) ou em pacientes idosos sem morbidade relacionada à acromegalia, albergando micro ou macroadenomas (83). Outra indicação seria em pacientes submetidos à radioterapia enquanto se aguarda seu efeito terapêutico, habitualmente tardio $(8,83,85)$.

O papel das drogas como terapia primária da acromegalia ainda está para ser melhor estabelecido. Um recente estudo multicêntrico americano mostrou eficácia similar da octreotida como terapia primária ou secundária (pacientes previamente tratados com cirurgia e/ou radioterapia) no que tange à redução do GH, normalização do IGF-1 e melhora dos sintomas (11). Entretanto, a redução tumoral no grupo primariamente tratado aconteceu em apenas $46 \%$ dos pacientes e somente em metade dos casos excedeu $50 \%$. Não houve tampouco correlação entre redução tumoral e diminuição dos niveis de GH e IGF-1 (11). 


\section{Agonistas Dopaminérgicos}

Os agonistas dopaminérgicos estimulam a secreção de $\mathrm{GH}$ em indivíduos normais. Em alguns acromegálicos, por um mecanismo ainda não esclarecido, essas drogas paradoxalmente suprimem a liberação do $\mathrm{GH}$. O composto mais utilizado tem sido a $\mathrm{BRC}$, mas há evidências recentes de que a cabergolina (12) e a quinagolida (99) seriam mais eficazes.

\section{Bromocriptina}

Eficácia clínica - Alguma redução na concentração sérica de $\mathrm{GH}$ acontece na maioria dos pacientes, mas niveis $<5 \mathrm{ng} / \mathrm{mL}$ foram observados apenas em aproximadamente $20 \%$, com normalização do IGF-1 em 10\% $(100,101)$. As respostas clínicas são altamente variáveis, com 14 a $94 \%$ dos pacientes apresentando melhora do bem-estar e redução de partes moles, da cefaléia, sudorese e artralgia $(85,100,101)$. Em alguns estudos, doses de até $90 \mathrm{mg} /$ dia foram utililizadas, mas há evidências de que poucos benefícios adicionais são ganhos quando se utilizam doses $>20 \mathrm{mg} /$ dia $(83,100,101)$. No tocante à redução tumoral, melhores resultados são observados em pacientes com hiperprolactinemia associada $(85,100)$. Em 62 acromegálicos, diminuição do tamanho do adenoma aconteceu em 29\%, geralmente após 6 a 7 meses de tratamento, mas redução importante foi vista apenas raramente $(100,101)$.

\section{Cabergolina}

Eficácia clínica - Os resultados de seis estudos com cabergolina (CAB) envolvendo 112 acromegálicos, nas doses de $0,3 \mathrm{mg} / \mathrm{semana}$ a $0,5 \mathrm{mg} /$ dia, revelaram resultados algo discordantes, com normalização média do $\mathrm{GH}$ em 37\% dos casos e do IGF-1 em 34\% $(12,50,102-105)$. No maior desses estudos, em que 64 pacientes foram tratados por até 40 meses, o uso da $\mathrm{CAB}$ resultou em níveis de $\mathrm{GH}<2 \mathrm{ng} / \mathrm{mL}$ em $46 \%$ dos pacientes e de IGF- $1<300 \mathrm{ng} / \mathrm{mL}$ em $39 \%$, com redução tumoral ocorrendo em $62 \%$ (105). Os me- 1hores resultados aconteceram em indivíduos com adenomas co-secretores de GH e prolactina, e níveis de IGF-1 $<750 \mathrm{ng} / \mathrm{mL}$ (105). Em 3 acromegálicos nãoresponsivos a $\mathrm{BRC}$, observamos após 3 meses de tratamento (na dose de $3 \mathrm{mg} /$ semana), redução média do $\mathrm{GH}$ para menos de $2,5 \mathrm{ng} / \mathrm{mL}$ e normalização do IGF1 em um paciente; nos demais, os níveis médios de $\mathrm{GH}$ baixaram para $6,6 \mathrm{ng} / \mathrm{mL}$ e $39 \mathrm{ng} / \mathrm{mL}$ (106). Na experiência da Dra. Annamaria Collao, de Nápoles, os melhores resultados são vistos em casos de adenomas mamossomatotróficos, que co-secretam PRL e GH (comunicação pessoal).

\section{Quinagolida}

Eficácia clínica - Em dois estudos envolvendo 28 acromegálicos, o uso da quinagolida permitiu normalização dos niveis de GH e IGF-1 em $43 \%$ dos pacientes $(103,107)$. Foi também relatado que a quinagolida, sozinha ou em combinação com a octreotida, produziu concentrações séricas normais de GH e IGF-1 em 58\% dos pacientes previamente resistentes a BRC e à octreotida (108).

\section{Análogos da Somatostatina}

A maior experiência mundial é com a octreotida $(8,83)$, que possui maior afinidade pelos receptores somatostínicos subtipos 2 e 5 , que são justamente os mais prevalentes na hipófise normal e tumoral $(109,110)$. Mais recentemente estão disponíveis também análogos somatostatínicos de ação prolongada (octreotida LAR e lanreotide $S R$ ), que possibilitam uma maior comodidade posológica para os pacientes $(111,112)$.

\section{Octreotida}

Eficácia clínica - A octreotida é 40 vezes mais potente do que a somatostatina natural (113). Com ela consegue-se redução do GH e IGF-1, assim como melhora clínica, em aproximadamente $90 \%$ dos pacientes (113115). A dose inicial habitual da octreotida é de $100 \mu \mathrm{g}$, 3 vezes/dia, por via subcutânea, mas alguns pacientes

Tabela 6. Eficácia da cabergolina em pacientes acromegálicos

\begin{tabular}{|c|c|c|c|c|}
\hline Autor (ref.) & $\mathbf{N}$ & Dose & $\begin{array}{l}\text { Normalização } \\
\text { do } G H(\%)\end{array}$ & $\begin{array}{l}\text { Normalização } \\
\text { do IGF-1 (\%) }\end{array}$ \\
\hline Cozzl et al (12) & 18 & $\begin{array}{l}0.5 \mathrm{mg} 2 \times \mathrm{sem} \\
\text { a } 0,5 \mathrm{mg} / \mathrm{dia}\end{array}$ & 28 & 28 \\
\hline Muratori et al (50) & 3 & $1-3 \mathrm{mg} / \mathrm{sem}$ & 100 & 100 \\
\hline Ferrari et al (102) & 6 & $0,3-1,2 \mathrm{mg} / \mathrm{sem}$ & 50 & 50 \\
\hline Colao et al (103) & 11 & $1 \mathrm{mg} 2 \times \mathrm{sem}$ & 0 & 0 \\
\hline Jackson et al (104) & 10 & $0,5 \mathrm{mg} / \mathrm{dia}$ & 20 & 20 \\
\hline Abs et al (105) & 64 & $1-7.5 \mathrm{mg} / \mathrm{sem}$ & 46 & 39 \\
\hline Vilar et al (106) & 3 & $1,5 \mathrm{mg} 2 \times \mathrm{sem}$ & 33 & 33 \\
\hline Total & 116 & & 38 & 34 \\
\hline
\end{tabular}


requerem o dobro dessa dosagem (97). Doses diárias $>600 \mu \mathrm{g} /$ dia raramente trazem algum benefício adicional para os pacientes $(97,113)$. Em 4 grandes séries, envolvendo 430 acromegálicos, o uso da octreotida resultou em níveis de $\mathrm{GH}<5 \mathrm{ng} / \mathrm{mL}$ em $43-51 \%$ (média de 46\%), $\mathrm{GH}<2,0 \mathrm{ng} / \mathrm{mL}$ em 18-46\% (média de $34,5 \%$ ) e normalização do IGF-1 em 20-61\% (média de 46\%) (115-118). Em outro estudo, normalização do IGF-1 ocorreu em 56 de 87 (64\%) pacientes e supressão do $\mathrm{GH}$ para menos de $2 \mathrm{ng} / \mathrm{mL}$ em $40 \%$ (119)

A resposta clínica com o uso da octreotida é geralmente rápida (97). Mais de $50 \%$ dos pacientes referem melhora da cefaléia - que pode ocorrer dentro de minutos após a administração da droga (114) -, astenia, artralgia, acne cística, bem como redução na sudorese e tamanho de mãos e pés $(97,115)$; cerca de $50 \%$ dos pacientes tornam-se normotensos e uma proporção semelhante melhora da apnéia do sono (97). Um efeito benéfico sobre a perfomance cardíaca foi recentemente relatado em pacientes cujo tratamento normalizou o IGF-1 e reduziu os níveis de $\mathrm{GH}$ para valores $<2,5 \mathrm{ng} / \mathrm{mL}$ (120). Desta forma, a octreotida poderia potencialmente diminuir a excessiva mortalidade cardiovascular nos acromegálicos.

O efeito da octreotida sobre a redução tumoral é discreto, variando de menos de $20 \%$ a mais de $50 \%$ do tamanho do tumor, mas na maioria dos casos é inferior a $50 \%(11,81,97)$. Em 4 séries, totalizando 366 pacientes, redução $>20 \%$ aconteceu em $39 \%$ (variação de 27 a 47\%), após 2 a 6 meses de tratamento (115-118). Contrastando com esse achado, Barkan et al relataram redução tumoral, de 20 a $45 \%$, em todos os 10 pacientes tratados (121). O efeito antiproliferativo dos análogos da somatostatina deve-se a mecanismos diretos de ação sobre os receptores específicos, desencadeando as vias de sinalização que inibem o ciclo celular, tais como a ativação de fosfotirosina fosfatases, a redução da produção de AMP cíclico, e a autofosforilação de receptor de EGF (122-123). Os mecanismos indiretos envolvem a supressão de fatores de crescimento locais e hormônios que estimulam o crescimento tumoral, além dos fatores que estimulam a angiogênese $(122,123)$.

O uso pré-operatório da octreotida, por 3 semanas a 6 meses, pode resultar em maior índice de remissão pós-cirúrgica $(121,124)$, bem como reduzir a permanência hospitalar e a morbimortalidade perioperatória decorrente de complicações cardíacas e respiratórias (125). Outros autores, contudo, não observaram benefícios da octreotida no que se refere aos niveis pós-operatórios de $\mathrm{GH}$ ou à ocorrência de complicações cirúrgicas (126).
O efeito colateral mais importante do tratamento prolongado ( $>1$ mês) com a octreotida é a colelitíase que ocorre em 20 a 30\% dos pacientes (81). $\mathrm{Na}$ maioria dos casos, os cálculos permanecem assintomáticos - somente cerca de $1 \%$ dos pacientes têm sintomas por ano de tratamento (83), que podem desaparecer espontaneamente em alguns deles $(81,83)$. Efeitos gastrointestinais - como, diarréia (o mais comum), náuseas, flatulência, dor abdominal, malabsorção de gorduras, etc -, são observados transitoriamente em 10-60\% dos pacientes, mas quase sempre desaparecem dentro de 2 a 3 semanas do início do tratamento (119). Cefaléia e tonturas também ocorrem (119). Bradicardia sem significado clínico ocorre em aproximadamente $25 \%$ dos pacientes $(81,119)$. Hipoglicemia pode raramente acontecer, por mecanismo ainda não estabelecido (97). Dor no local das injeções é uma queixa de 7,5\% dos pacientes (119).

Alguns parâmetros podem ser utilizados para se prever a resposta terapêutica aos análogos da somatostatina. $O$ teste agudo de sensibilidade a octreotida consiste na administração subcutânea de $100 \mu \mathrm{g}$ da droga, seguida de dosagens de $\mathrm{GH}$ a cada 30 minutos ao longo de 8 horas. É considerado positivo quando houver redução nos níveis de $\mathrm{GH}$ maior que $50 \%$, e tem valor preditivo positivo de $56 \%$ para resposta ao tratamento crônico (127). Outra opção é a cintilografia com octreotida marcada com ${ }^{111} \mathrm{In}$ (111 In-DTPA-Phe-D-OCT) que tem valor preditivo positivo de $73-100 \%(126,127)$, mas valor preditivo negativo de $50 \%$ (128).

\section{2) Análogos somastostatínicos de ação prolongada}

A primeira a ser lançada foi a droga francesa lanreotide que na sua apresentação de liberação lenta (Somatuline ${ }^{\circledR}$ L.P.) pode ser aplicada na dose de $30 \mathrm{mg}$ a cada 10 a 14 dias, por via intramuscular $(111,112)$. Posteriormente, foi desenvolvida uma forma depot da octreotida (Sandostatin ${ }^{\circledR} L A R$ ), com duração de ação de 28 a 42 dias (129). A dose usual da octreotida LAR é 20-30 mg IM a cada 4 semanas (129). Doses maiores (até $40 \mathrm{mg}$ ) geralmente não proporcionam benefícios adicionais (119).

Em 98 acromegálicos, o uso do $30 \mathrm{mg}$ do lanreotide, a cada 10-14 dias, propiciou, em média, níveis de $\mathrm{GH}<5 \mathrm{ng} / \mathrm{mL}$ em $81 \%$ dos casos (variação de 68 $89 \%$ ), GH $<2 \mathrm{ng} / \mathrm{mL}$ em $50 \%$ (variação de $27-76 \%$ ), normalização de IGF-1 em 50\% (variação de 38-63\%), e redução tumoral maior que $20 \%$ em $16 \%$ (variação de 13-17\%) (130-132). Considerando os mesmos 
parâmetros, os resultados obtidos com a octreotida LAR (20-40 mg, a cada 28-42 dias) em 123 acromegálicos foram os seguintes: niveis de $\mathrm{GH}<5$ $\mathrm{ng} / \mathrm{mL}$ em $93 \%$ (variação de $86-100 \%$ ), $\mathrm{GH}<2 \mathrm{ng} / \mathrm{mL}$ em $56 \%$ (variação de 54-64\%), normalização de IGF-1 em $66 \%$ (variação de $64-88 \%$ ), e redução tumoral $>20 \%$ em 65\% (variação de 29 a 72\%) (133-135).

Um estudo recente comparou octreotida LAR e lanreotide (136). Ambas as drogas mostraram-se igualmente eficazes em reduzir os níveis médios de $\mathrm{GH}$ para menos de $2,5 \mathrm{ng} / \mathrm{mL}$, mas a octreotida LAR proporcionou níveis médios de $\mathrm{GH}$ significativamente menores (136). A octreotida LAR mostrou-se também eficaz em reduzir ou normalizar IGF-1 e GH em alguns pacientes resistentes ao lanreotide (137). Cura da acromegalia foi recentemente relatada em dois casos de acromegalia (um micro e um macrodenoma) tratados inicialmente com octreotida SC (por 4 a 7 anos) e depois com octreotida LAR (138). Um ano após a suspensão da octreotida LAR, os pacientes continuavam assintomáticos e os níveis de IGF-1 e do GH (basal e após supressão com glicose) permaneciam normais, com desaparecimento da imagem do microadenoma e significante redução de volume do macroadenoma (138).

Os efeitos colaterais mais comuns da octreotida LAR são disconforto, leve a moderado, no local da injecção e queixas gastrointestinais (cólicas abdominais, diarréia e constipação) (119). Estas últimas têm sido relatadas em até $50 \%$ dos pacientes, mas freqüentemente duram apenas 1 a 2 dias e podem não recidivar após as injeções subseqüentes $(119,128)$. Em 101 pacientes tratados por até 30 meses, surgiram cálculos biliares em quatro pacientes e microlitíase em outros quatro (134). As reações adversas ao lanreotide SR incluem reações gastrointestinais (náuseas, dor abdominal, diarréia) que geralmente persistem por $1 \mathrm{a}$ 2 dias após a injecção e são pouco intensas (119). Litíase biliar foi observada em 5 de $32(15,6 \%)$ pacientes tratados por 6 meses a 1 ano $(119,132)$.

\section{Novas Perspectivas Terapêuticas}

Recentemente foi desenvolvido o pegvisomant (B2036-PEG), um antagonista seletivo do receptor do $\mathrm{GH}$ (GH-R) (139). Esse hormônio polipeptídeo,

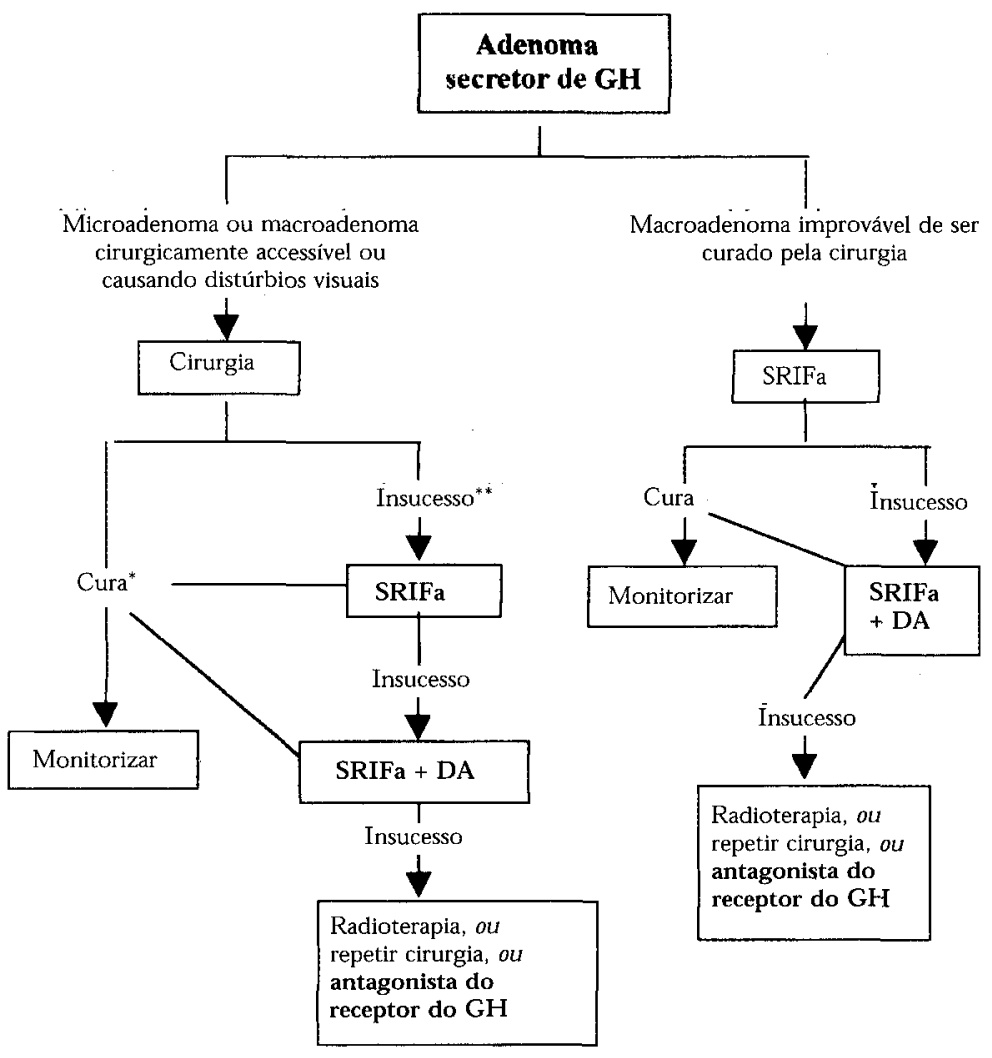

Figura 1. Algoritmo proposto para o manuseio dos adenomas secretores de $\mathrm{GH}$.

* GH pós-supressão de glicose (OGT) <2 ng/ml (RIE) e IGF-1 normal; ** GH pós-OGT >2 ng/mL (RIE) e IGF-1 elevado; SRIFa: análogo da somatostatina; DA: agonista dopaminérgico. Em pacientes com hiperprolactinemia associada e/ou níveis não muito elevados de GH e IGF-1, cabergolina pode ser testada antes do SRIFa. 
Tabela 7. Eficácia comparativa, em termos percentuais, entre drogas e cirurgia no manuseio da acromegalia

\begin{tabular}{|c|c|c|c|c|}
\hline & \multirow[t]{2}{*}{ Ref. } & \multicolumn{3}{|c|}{ \% médio de pacientes com: } \\
\hline & & $\mathrm{GH}<5 \mathrm{ng} / \mathrm{ml}$ & $\mathrm{GH}<2 \mathrm{ng} / \mathrm{ml}$ & IGF-1 normal \\
\hline Bromocriptina & 100,101 & 20 & -- & 10 \\
\hline Cabergolina & $12,50,102-106$ & - & 38 & 34 \\
\hline Octreotida & $115-118$ & 47 & 34 & 46 \\
\hline Lanreotide & $130-132$ & 82 & 50 & 50 \\
\hline Octreotida LAR & $133-135$ & 93 & 56 & 66 \\
\hline B2036-PEG & 140,141 & - & - & \pm 90 \\
\hline \multicolumn{5}{|l|}{ Cirurgia } \\
\hline Microadenomas & $66,82,87,89,90$ & - & $40-91$ & - \\
\hline Macroadenomas & $66,82,87,89,90$ & 一- & $23-53$ & - \\
\hline
\end{tabular}

obtido pela técnica do DNA recombinante, é um análogo do GH com nove mutações, as quais alteram a capacidade de ligação dessa molécula, impedindo a dimerização do GH-R e a ação do $\mathrm{GH}$, mas não inibe a secreção do $\mathrm{GH}(139,140)$. Resultados iniciais do primeiro estudo publicado demonstraram que essa droga é bem tolerada e que, na dose de $20 \mathrm{mg} / \mathrm{dia} \mathrm{SC}$, permitiu normalização dos nivveis de IGF-1 e melhora clínica significativa em 89\% de 112 agromegálicos tratados, incluindo aqueles resistentes aos análogos da somatostatina $(140,141)$. Entretanto, em um estudo alemão com 107 acromegálicos, normalização do IGF-1 somente ocorreu em $58,6 \%$ dos pacientes medicados com $20 \mathrm{mg} /$ dia (142). Antagonistas do GHRH também vêm sendo pesquisados (5).

Outros estudos vêm sendo desenvolvidos para a obtenção de análogos de somatostatina com maior afinidade pelos receptores somatostatínicos (SSTR). Nesse contexto, observou-se que drogas como o BIM23910, BIM-23197 e o MK-678, considerados análogos de segunda geração, têm maior afinidade e seletividade pelos SSTR do tipo 2 do que a octreotida e o lanreotide (143). Análogos não-peptídicos da somatostatina, que poderiam ser administrados por via oral, também estão sendo pesquisados (143). Recentemente, foi demonstrado o potencial papel da terapia gênica mediada por adenovírus para o tratamento dos adenomas hipofisários (144).

\section{COMENTÁRIOS}

Da análise sobre a eficácia das drogas no manuseio da acromegalia depreendem-se as seguintes observações:

1. Os análogos somatostatínicos (SRIFa) são as drogas mais eficazes para o manuseio da acromegalia, tendo como principal inconveniente o elevado custo do tratamento. A octreotida LAR atualmente desponta com a melhor opção pelo fato de poder ser administrada em injeções IM mensais.
2. A utilidade dos SRIFa como terapia primária para a acromegalia fica comprometida por seu limitado efeito em reduzir o tamanho do adenoma hipofisário. No entanto, deve ser considerada em pacientes com baixa possibilidade de cura cirúrgica (por ex., grandes macroadenomas ou tumores invasivos), desde que não haja ameaça à visão ou à função neurológica. Nesses casos, os análogos somatostatínicos parecem propiciar um percentual de redução e normalização dos níveis de GH superiores aos obtidos com a cirurgia e à radioterapia, sem levar ao hipopituitarismo. $O$ desenvolvimento de compostos mais potentes e com maior afinidade e seletividade pelos receptores da somatostatina poderá resultar em redução tumoral mais acentuada. Por sua maior segurança, os SRIFa despontam também como uma atraente alternativa para a radioterapia, em caso de insucesso cirúrgico (figura1).

3. Quando se optar pela terapia medicamentosa, os agonistas dopaminérgicos (DA), devido ao seu menor custo, podem ser tentados inicialmente, sobretudo nos casos com níveis de GH e IGF-1 não muito elevados e/ou hiperprolactinemia associada, quando têm maior eficácia. Os DA podem também ser úteis como terapia adicional nos pacientes sem resposta satisfatória aos SRIFa. Os resultados preliminares com a cabergolina (CAB) são bastante animadores, mostrando, no tocante à normalização do GH e IGF-1, nítida superioridade em relação a BRC e eficácia algo comparável à da octreotida , com a vantagem de poder ser administrada em uma a duas tomadas semanais, por via oral. A utilização da $\mathrm{CAB}$ em maior número de pacientes permitirá uma melhor definição sobre seu real papel no manuseio da acromegalia.

4. Os antagonistas do receptor do GH surgem como drogas bastante promissoras para os casos de hipersecreção persistente de $\mathrm{GH}$ após a cirurgia ou resistência a octreotida (figura1). Têm como inconveniente maior, o fato de não levarem à redução tumoral. 


\section{REFERÊNCIAS}

1. Kovacs K. Horvath E. Pathology of pituitary tumors Endocrinol Metab Clin North Am 1987: 16:529-51.

2. Molitch ME, Russell EJ. The pituitary "incidentaloma". Ann Intern Med 1990; 1 12:925-31.

3. Hall WA, Luciano MG, Doppman JL, et al. Pituitary magnetic resonance imaging in normal human volunteers occult adenomas in the general population. Ann Intern Med 1994; 120:817-20.

4. Chanson P. Traitement des adenomes hypophysaires. Presse Med 1998;27:2077-97

5. Shimon I, Melmed S. Management of pituitary tumors. Ann Intern Med 1998; 129:472-83.

6. Klibansky A, Zervas NT. Diagnosis and management of hormone-secreting pituitary adenomas. N Engl J Med $1991: 324: 822-31$.

7. Molitch $\mathrm{M}$, Thorner MO, Wilson $\mathrm{C}$. Therapeutic controversy: management of prolactinomas. J Clin Endocrinol Metab 1997:82:996-1000

8. Melmed S, Ho K, Klibansky A, Reichlin S, Thorner M. Clinical review 75: Recent advances in pathogenesis, diagnosis and management of acromegaly. J Clin Endocrinol Metab $1995 ; 80: 3395-402$

9. Liuzzi A, Tassi V, Pirro MT, Zingr $\|$ lo M. Nonfunctioning adenomas of the pituitary. Metabolism 1996;45(suppl 1):80-2.

10. Sassolas $G$. Medical therapy with somatostatin analogues for acromegaly. Eur J Endocrinol 1995; 133:675-7.

11. Newman CB, Melmed S, George A, Torigan D. Octreotide as primary therapy for acromegaly. J Clin Endocrinol Metab 1998;83:3034-40

12. Cozzi R, Attanasio R, Barausse M, Dallabonzanna D. Cabergoline in acromegaly: a renewed role for dopamine agonist treatment? Eur J Endocrinol 1998: 139:516-21.

13. Warnet A, Harris AG, Renard $E$, et al. A prospective multicenter trial of octreotide in 24 patients with visual defects caused by nonfunctioning and gonadotropin-secreting pituitary adenomas, Neurosurgery 1997:41:786-97.

14. Chanson $P$, Weintraub BD, Harris AG. Octreotide therapy for thyrold-stimulating hormone-secreting pituitary adenomas. A follow-up of 52 patients. Ann Intern Med 1993; 119:236-40.

15. Vilar L, Castellar E. Hiperprolactinemia - Investigação diagnóstica e tratamento. In: Vilar L, Castellar E, Moura E, Leal $\mathrm{E}$, et al, eds. Endocrinologia Clínica. Rio de Janeiro:Medsi, 1999: $3-20$

16. Bronstein MD. Hiperprolactinemia. In: Wajchenberg BL, ed Tratado de Endocrinologia Clínica. São Paulo:Roca, 1992: 135-64

17. Molitch ME. Management of prolactinomas, Endocrinol Metab Clin North Am 1999:28:143-69.

18. Schlechte J, Dolan $K$, Sherman B. The natural history of untreated hyperprolactinaemia: a prospective analysis. J Clin Endocrinol Metab 1989;68:412-18.

19. Martin TL, Kim B, Malarkey WB. The natural history of idiopathic hyperprolactinaemia: a prospective analysis, J Clin Endocrinol Metab 1985; 60:855-8

20. Sisam DA, Sheehan JP, Sheeler LR. The natural history of untreated microprolactinomas. Fertil Steril 1987:48:67-71.
21. Cunnah D, Besser M. Management of prolactinomas. Clin Endocrinol (Oxf) 1991:34:231-5.

22. Besser GM, Parke L, Edwards CR, Forsyth IA, McNeilly AS Galactorrhoea: successsful treatment with reduction of plasma prolactin levels by bromergocrytine. Br Med J 1972;3:669-72

23. Weingrill CO, Mussio W, Moraes CRS, Portes E, et al.Longacting oral bromocriptine (Parlodel SRO) in the treatment of hyperprolactinemia. Fertil Steril 1992;57:331-5.

24. Halperin I, Rodreigues MD, Cardenal C, Casamitjana R, et al. Treatment of pltuitary macroadenomas secreting PRL, HGH or ACTH with long-acting bromocriptine. J Endocrinol Invest 1987: 10:277-82

25. Grossman A, Ross R, Wass JA, Besser GM. Depot-bromocriptine treatment for prolactinomas and acromegaly. Clin Endocrinol (Oxf) 1986:24:231-8.

26. Ciccarelli E, Grottolli S, Miolla C, Avantaneo T, et al. Double blind randomized study using oral or injectable bromocriptine in patients with hyperprolactinaemia. Clin Endocrinol (Oxi) 1994:40:193-8.

27. Molitch ME. Prolactinoma. In: Melmed S, ed. The Pituitary Boston:Blackwell Scientific, 1995:443-77.

28. Vance ML, Evans WS, Thorner MO. Bromocriptine. Ann Intern Med 1984; 100:78-91

29. Thorner MO, Martin WH, Rogol AD, et al. Rapid regression of pituitary prolactinomas during bromocriptine treatment. $J$ Clin Endocrinol Metab 1980;51:438-45.

30. Molitch ME, Elton RL, Blackwell RE, Caldwell B. Bromocriptine as primary therapy for prolactin-secreting macroadenomas: results of a prospective multicenter study. J Clin Endocrinol Metab 1985;60:698-705

31. Vilar L, Burke CW. Quinagolide efficacy and tolerability in hyperprolactinaemic patients who are resistant to or intolerant of bromocriptine. Clin Endocrinol (Oxf) 1994:41:821-6.

32. Pellegrini I, Rasolonjanahary $R$, Gunz $G$, et al. Resistance to bromocriptine in prolactinomas. J Clin Endocrinol Metab 1989:69:500-9.

33. Colao A, Di Sarno A, Sarnacchiaro F, Ferone D, et al. Prolactinomas resistant to standard dopamine agonists respond to chronic cabergoline treatment, J Clin Endocrinol Metab 1997;82:876-83.

34. Vance ML, Thorner MO. Prolactinomas. Endocrinol Metab Clin North Am 1987;16:731-54.

35. Thorner MO, Vance ML, Horvath E, Kovacs K. The anterior pituitary. In: Wilson JD, Foster DW, eds. Williams Textbook of Endocrinology. Philadelphia:Saunders, 1992:221-310.

36. Biller MB, Molitch ME, Vance ML. Treatment of prolactinsecreting macroadenomas with the once-weekly dopamine agonisł cabergoline. J Clin Endocrinol Metab 1996:81:2338-43

37. Turner TH, Cookson JC, Wass JAH, Drury PL, et al. Psychotic reactions during treatment of pituitary tumours with dopamine agonists. Br Med J 1984;289:1 101-3.

38. Kok JG, Bartelink AKM, Schulte BPM, et al. Cerebrospinal fluid rhinorrhea during treatment with bromocriptine for prolactinoma. Neurology 1985;35:1 193-5.

39. Katz E, Schran HF, Adashi EY. Successful treatment of prolactin-producing pltultary macroadenoma with intravaginal bromocriptine mesylate: a novel approach to intolerance of oral therapy. Obstet Gynecol 1989;75:517-20.

40. Motta T, de Vincentiis S, Marchini M, Colombo N, D'Alber- 
ton A. Vaginal cabergoline in the treatment of hyperprolactinemic patients intolerant to oral dopaminergics. Fertil Steril 1996:65:440-2.

41. Bouloux PGM, Besser GM, Grossman A, Moult PJA, Clinical evaluation of lysuride in the management of hyperprolactinaemia. Br Med J 1987;294:1323-4.

42. Stracke $H$, Heinlein $W$. Dopamine agonists in the treatment of hyperprolactinemia. Comparison between bromocriptine and lisuride. Arzneimittel Forschung 1986;36:1834-6.

43. Verhelst JA, Froud AL, Touzel R, Wass JAC. Besser GM, Grossman A. Acute and long-term effects of once-daily bromocriptine and a new long-acting dopamine agonist quinagolide, in the treatment of hyperprolactinaemia. A double-blind study. Acta Endocrinol (Copenh) 1991;125:385-91.

44. Homburg R, West C. Brownell J, Jacobs HS. A double-blind study comparing a new non-ergot, long-acting dopamine agonist, CV 205 502, with bromocriptine in women with hyperprolactinaemia. Clin Endocrinol (Oxf) 1990:32:565-71.

45. Tabarin A, Catargi B. Treatment of macroprolactinomas with quingolide (Norprolac). Ann Endocrinol (Paris) 1997; $58: 87-94$

46. Ferrari C, Barbieri C, Caldara R, Mucci M, et al. Long-lasting prolactin-lowering effect of cabergoline, a new dopamine agonist, in hyperprolactinaemic patients. J Clin Endocrinol Metab 1986;63:941-5.

47. Rains CP, Bryson HM, Fitton A, et al. Cabergoline: a revlew of its pharmacological properties and therapeutic potential in the treatment of hyperprolactinaemia and inhibition of lactation. Drugs 1995:49:255-79.

48. Verhelst J, Abs R, Maiter D, van den Bruel A, Vandeweghe $M$, et al. Cabergoline in the treatment of hyperprolactinemia: a study in 455 patients. J Clin Endocrinol Metab 1999;84:2518-22

49. Webster J, Piscitelli G, Polli A, D'Alberton A, et al. The efficacy and tolerability of long-term cabergoline therapy in hyperprolactinaemic disorders: an open, uncontrolled, multicentre study, Clin Endocrinol (Oxf) 1993;39:323-30

50. Muratori M, Arosio M, Gambino GG, Romano C, Biella O. Faglia $G$. Use of cabergoline in the long-term treatment of hyperprolactinemic and acromegalic patients. J Endocrinol Invest 1997:20:537-46.

51. Ferrari $\mathrm{Cl}$, Abs R, Bevan JS, Brabant $\mathrm{G}$, et al. Treatment of macroprolactinoma with cabergoline: a study of 85 patients. Clin Endocrinol (Oxt) 1997:46:409-13.

52. Colao A, Di Sarno A, Landi ML, Scavuzzo F, et al. Macroprolactinoma shrinkage during cabergoline treatment is greater in naive patients than in patients pretreated with other dopamine agonists: a prospective study in 110 patients. J Clin Endocrinol Metab 2000;85:2247-52.

53. Webster J, PIscitelli G, Polli A, Ferrari Cl, et al. A comparison of cabergoline and bromocriptine in the treatment of hyperprolactinemic amenorrhea. Cabergoline comparative study group. N Engl J Med 1994;331:904-9.

54. De Rosa M, Colao A, Dí Sarno A, Ferone D, et al. Cabergoline treatment rapidly improves gonadal function in hyperprolactinemic males: a comparison with bromocriptine. Eur J Endocrinol 1998; 138:286-93.

55. Delgrange $E_{s}$ Maiter D, Donckier J. Effects of the dopamine agonist in patients with prolactinoma intolerant ou resistant to bromocriptine. Eur J Endocrinol 1996;134:454-6.

56. Colao A, Ferone D, Marzullo P, et al. Effect of different dopaminergic agents in the treatment of acromegaly. $\mathbf{J}$ Clin Endocrinol Metab 1997:82:518-23.
57. Vilar L, Freltas $M C$, Leite $V$, Canadas $V$, et al. Cabergolina em pacientes com prolactinomas resistentes ou intolerantes à bromocriptina. Arq Bras Endocrinol Metab 1999:43(supl.2):S421.

58. Faglia $G$. Should dopamine agonist treatment for prolactinomas be life-long? Clin Endocrinol (Oxf) 1991;34:173-4.

59. van' + Verlaat JW, Croughs RJM. Withdrawal of bromocriptine after long-term therapy for macroprolactinomas; effect on plasma prolactin and tumour size. Clin Endocrinol (Oxf) 1991;34:175-8.

60. Johnston DG, Hall K, Kendall-Taylor P, Patrick D, et al. Effect of dopamine agonist withdrawal after long-term therapy in prolactinomas. Studies with high-definition computerised tomography, Lancet 1984;2:187-92.

61. Ciccarelli E, Grottoli S, Razzore P, Gaia D, et al. Long-term treatment with cabergoline, a new long-lasting ergoline derivative, in idiopathic or tumorous hyperprolactinaemia and outcome of drug-induced pregnancy. J Endocrinol Invest 1997:20:547-51.

62. Molitch $M$. Pregnancy and the hyperprolactinemic woman. N Engl J Med 1985;312: 1365-70.

63. Vance ML. New directions in the treatment of hyperprolactinemia. Endocrinologist 1997;7:153-9.

64. Robert E, Musatti L, Piscitelli $G$, et al. Pregnancy outcome after treatment with the ergot derlvative cabergoline. Reprod Toxicol 1996; 10:333-7.

65. Laws ER, Pituitary surgery, Endocrinol Metab Clin North Am 1987; 16:647-65.

66. Laws ER Jr, Thapar K. Pituitary surgery. Endocrinol Metab Clin North Am 1999:28:119-31.

67. Tyrell JB, Lamborn KR, Hannegan LT, et al. Transsphenoidal microsurgical therapy of prolactinomas: initial outcomes and long-term results. Neurosurgery 1999;44:254-63.

68. Tsang RW. Brierley JD. Panzarella T, et al. Role of radiation therapy in clinically hormonally active pituitary adenomas. Radiother Oncol 1996:41:45-53.

69. Plowman PN. Pituitary adenoma radiotherapy - when and how? Clin Endocrinol (Oxf) 1999;51:265-72.

70. Martinez R, Bravo G, Burzaco J, Rey G. Pituitary tumors and gamma-knife surgery. Clinical experience with more than two years of follow-up. Stereotact Funct Neurosurg 1998; 70 (suppl. 1):110-8.

71. Morange-Ramos I, Régis J, Dufour $\mathrm{H}$, Andrieu JM, et al. Short-term endocrinological results after gamma-knife surgery of pituitary adenomas. Stereotact Funct Neurosurg 1998:70(suppl. 1):127-38.

72. Shimon I, Yan X, Taylor JE, Weiss MH, Cutler MD, Melmed S. Somatostatin receptor (SSTR) subtype-selective analogues differentially supress in vitro growth hormone and prolactin in human pituitary adenomas. Novel potential therapy for functional pituitary fumors. J Clin Invest 1997; 100:2386-92.

73. Melmed S. Acromegaly. N Engl J Med 1990;322:966-77.

74. Alexander L, Appleton D, Hall R, Ross WM, Wilkinsom R. Epidemiology of acromegaly in the Newcastle region. Clin Endocrinol (Oxf) 1980;12:71-9.

75. Bengtsson BA, Eden S, Ernest I, Oden A, Sjogren B. Epidemlology of acromegaly and long-term survival in a study of 166 cases diagnosed between 1955 and 1984. Acta Med Scand 1988:223:327-35.

76. Barkan Al. Acromegaly: diagnosis and therapy. Endocrinol Metab Clin North Am 1989;18:277-310. 
77. Wright $A D$, Hill $D M$, Lowy $C$, Frazer TR. Mortality in acromegaly. Q J Med 1970;34: 1-16.

78. Rajasoorya C, Holdaway IM, Wrightson. Determinants of clinical outcome and survival in acromegaly. Clin Endocrinol (Oxf) 1994;41:95-102.

79. Bates AS, Van't Hoff, Jones JM, Clayton RN, Does treatment of acromegaly alter life expectancy? Metabolism 1995:44(Suppl 1):1-5.

80. Orme SM, MCNally RJQ, Cartwright RA. Mortality and cancer incidence in acromegaly: a retrospective cohort study. J Clin Endocrinol Metab 1998;83:2730-4.

81. Melmed s, Jackson I, Kleinberg D, Klibansky A. Current treatment guidelines for acromegaly. J Clin Endocrinol Metab 1998:83:2646-52

82. Sheaves $R$, Jenkins $D$. Blackburn $P$, et al. Outcome of transphenoidal surgery for acromegaly using strict criteria for surgical cures. Clin Endocrinol (Oxf) 1996;407-14.

83. Acromegaly therapy Consensus Development Panel. Benefits versus risks of medical therapy for acromegaly. Am J Med 1994;97:468-73

84. Giustina A, Barkan A, Casanueva FF, et al. Criteria for cure in acromegaly: a consensus statement. J Clin Endocrinol Metab 2000;85:526-9.

85. Vilar L, Leal $E$, Oliveira $S \mathrm{Jr}$. Diagnóstico e tratamento da acromegalia. In: Vilar L, Castellar E, Moura E, Leal E, et al, eds. Endocrinologia Clínica. Rio de Janeiro: Medsi, 1999:21-35.

86. Ross DA, Wilson CB. Results of transsphenoidal surgery for growth hormone-secreting pitultary adenoma in a series of 214 patients. J Neurosurg 1988;68:854-67.

87. Post KD, Biller BJ, Adelman LS, et ai. Selective transsphenoidal adenomectomy in women with galactorrheaamenorrhea. JAMA 1979:242:158-62.

88. Davis DH, Laws ER Jr, Ilstrup DM, et al. Results of surgical treatment for growth hormone pltuitary adenoma. J Neurosurg 1993:79:70-5

89. Jenkins D, O'Brien I, Johnson A, Shakespear $E$, et al. The Birmingham pituitary database: auditing the outcome of the treatment of acromegaly. Clin Endocrinol (Oxf) $1995 ; 43: 517-22$

90. Ahmed S, Elsheikh M. Stratton IM, Page RC, Adams CB, Wass JA. Outcome of transphenoidal surgery for acromegaly and its relationship to surgical experience Clin Endocrinol (OxI) 1999:50:561-7.

91. Laws ER. Results of transphenoidal microsurgery management of acromegaly. In: Wass JAH, ed. Treating Acromegaly. Bristol: Journal of Endocrinology, 1994:59-63.

92. Halberg FE, Sheline GE. Radiotherapy of pituitary tumors Endocrinol Metab Clin North Am 1987;667-84.

93. Jenkins PJ, Elliot EL, Carson MN, Bates PR, on behalf of The UK National Acromegaly Register Study Group. Proc 82 Annual Meeting of the Endocrine Society, Toronto, Canada, 2000 (Abstract P1-2163).

94. Barkan AL, Halasz I, Dornfield KJ, et al. Pituitary irradiation is ineffective in normalizing plasma insulin-like growth factor I in patients with acromegaly. J Clin Endocrinol Metab 1997:82:3187-91.

95. Jackson I, Norén G. Role of gamma knife therapy in the management of pltultary tumors. Endocrinol Metab Clin North Am 1999:28: 133-42.

96. Landolt AM, Haller D, Lomax N, Scheib S, et al. Stereotactic radiosurgery for recurrent surgically treated acromegaly: a comparison with fractionated radiotherapy. J Neurosurg 1998:88:1002-8.

97. Wass JAH. Treatment of acromegaly with octreotide. In: Wass JAH, ed. Treating Acromegaly. Bristol:Journal of Endocrinology, 1994:151-63.

98. Flogstad AK, Halse J, Grass P, et al. A comparison of octreotide, bromocriptine, or a combination of both drugs in acromegaly. J Clin Endocrinol Metab 1994;79:461-5.

99. Jacquet P. CV 205-502: a more effective dopamine agonist in the treatment of acromegaly? Eur J Endocrinol $1995: 132: 557-8$.

100.Scanlon MF. Dopamine agonists in the treatment of acromegaly, In: Wass JAH, ed. Treating Acromegaly. Bristol:Journal of Endocrinology, 1994:139-45.

101.Jaffe CA, Barkan AL. Treatment of acromegaly with dopamine agonists. Endocrinol Metab Clin North Am 1992;21:713-25.

102.Ferrarl C, Paracchi A, Romano C, Gerevinl G, et al. Longlasting lowering of serum growth hormone and prolactine by single and repetitive cabergoline administration in dopamine responsive acromegalic patients. Clin Endocrinol (Oxi) 1988;29:467-76.

103.Colao A, Ferone D, Marzullo P, et al. Effect of different dopaminergic agents in the treatment of acromegaly. $J$ Clin Endocrinol Metab 1997:82:518-23.

104.Jackson SNJ, Fowler J, Howlet † TA. Cabergoline treatment of acromegaly: a preliminary dose finding study. Clin Endocrinol (Oxf) 1997;46:745-9.

105.Abs R, Verhelst J, Maiter AD, Van Acker K, et al. Cabergoline in the treatment of acromegaly: a study of 64 patients. J Clin Endocrinol Metab 1998;83:374-8

106. Vilar L, Freitas MC, Leite V, Canadas V, et al. Cabergolina no tratamento da acromegalia. Arq Bras Endocrinol Metab 1999:43(supl. 2): $\$ 426$

107.Chlodini PG, Attanasio R, Coozzl R, Dallabonzana D, et al CV 205-502 in acromegaly. Acta Endocrinol (Copenh) 1993; 128:389-93.

108. Lombardi $G$, Colao A, Ferone D, Surnacchiaro F, et al. CV 205-502 treatment in therapy resistant acromegalic patients. Eur J Endocrinol 1995; 132:559-64.

109. Raulf F, Perez J, Hoyer D, Bruns C. Differential expression of five somatostatin receptor subtypes in the CNS and peripheral tissues, Digestion 1994:55:46-53.

110.Weckbecker $G$, Raulf F, Stoltz B. Bruns C. Somatostatin analogs for diagnosis and treatment of cancer. Pharmac Ther 1993;60:245-64

111. Heron I, Thomas F, Dero M, et al. Pharmacokinetics and efficacy of a long-acting formulation of the new somatostatin analog BIM 230I4 in patients with acromegaly. J Clin Endocrinol Metab 1993:76:721-7.

112.Sheppard MC. Stewart PM. Somatostatin analogs in treating acromegaly, Endocrinologist 1995:5:456-9,

113.Lamberts SW, van der Lely AJ, de Herder WW, Hofland LJ. Octreotide. N Engl J Med 1996:334:246-54.

114. Lamberts SWJ. The role of somatostatin in the regulation of anterlor pitultary hormone secretion and the use of its analogues in the treatment of human pituitary tumours. Endocr Rev 1988:9:417-36

115.Ezzat S, Snyder PJ, Young WF, Boyajy LD, et al. Octreotide treatment of acromegaly: a randomized multicenter study. Ann Intern Med 1992:117:711-8. 
116.Sassolas $G$, Harris $A G$, James Deidier A. Long-term effect of incremental doses of the somatostatin analog SMS 201-995 in 58 acromegalic patients. French SMS 201-995 Acromegaly Study Group. J Clin Endocrinol Metab 1990:71:391-7.

117.Vance ML, Harris AG. Long-term treatment of 189 acromegalic patients with the somatostatin analog octreotide. Arch Intern Med 1991; 151:573-8.

118.Arosio M, Machelli S, Rossi CM, Casati $G$, et al. Effects of treatment with octreotide in acromegalic patients- a multicenter italian study. Italian Multicenter Octreotide Study Group. Eur J Endocrinol 1995; 133:430-9.

119.Newman CB. Medical therapy for acromegaly. Endocrinol Metab Clin North Am 1999:28:171-90.

120.Collao A, Cuocolo A, Marzullo P, Nicolai E, et al. Effects of 1-year treatment with octreotide on cardiac perfomance in patients with acromegaly, J Clin Endocrinol Metab 1999;84:17-23.

121.Barkan AL, Lloyd RV, Chandler WF, et al. Preoperative treatment with the long-standing somatostatin analog SMS 201-295: shrinkage of invasive pituitary macroadenomas and improved surgical remission rate in acromegaly. J Clin Endocrinol Metab 1988:67:1040-8.

122. Baracat S, Melmed S. Reversible shrinkage of a growth hormone-secreting pituitary adenoma by a long actingsomatostatin analogue, octreotide. Arch Intern Med 1989; 1443-5.

123. Pollak MN, Schally AV. Mechanisms of antineoplastic action for somatostatin analogs. Proc Soc Exp Biol Med 1998:217:143-52.

124.Stevenaert A, Beckers A. Presurgical octreotide treatment in acromegaly, Acta Endocrinol 1993; 129(suppl. 1);13-7.

125. Colao A, Ferone D, Cappabianca P, et al. Effect of octreotide pretreatment on surgical outcome in acromegaly. J Clin Endocrinol Metab 1997:82:3308-14.

126.Kristof RA, Stoffel-Wagner B, Klingmuller D, Schramm J. Does octreotide treatment improve the surgical results of macroadenomas in acromegaly? A randomized study. Acta Neurochir (Wien) 1999;141:399-405.

127. Colao A, Ferone D, Lastoria S, Marzullo P, Cerbone G, et al. Prediction of efficacy of octreotide therapy in patients with acromegaly. J Clin Endocrinol Metab 1996:81:2356-62.

128. Broson-Chacot F, Housard C. Ajzenberg C, Nocaudie M, et al. Somatostatin receptor imaging in somatotroph and non-functioning pituitary adenomas: correlation with hormonal and visual responses to octreotide. Clin Endocrinol (Oxf) 1997:47:589-98.

129, Gillis JC, Noble S, Goa KL. Octreotide long-acting release (LAR). A review of its pharmacologic properties and therapeutic use in the management of acromegaly. Drugs 1997:53:681-99.

130.Morange I, De Boisvilliers F, Chanson P, et al. Slow release lanreotide treatment in acromegalic patients previously normalized by octreotide. J Clin Endocrinol Metab 1994:79: 145-51.

131. Giustl M, Gussonl G, Cuttica CM, Giordano G. Effectlveness and tolerability of slow relase lanreotide treatment in active acromegaly: six month report on an italian multicenter study, Italian Multicenter Slow Release Lanreotide Study Group. J Clin Endocrinol Metab 1996:81:2089-97.
132. Caron P, Morange-Ramos I, Cogne M, Jacquet P. Three year follow-up of acromegalic patients treated with intramuscular slow-release lanreotide. J Clin Endocrinol Metab 1997;82:18-22.

133.Stewart PM, Kane KF, Stewart SE, Lancranjan 1, et al. Depot long-acting somatostatin analog (Sandostatin LAR) is an effective treatment for acromegaly. J Clin Endocrinol Metab 1995:80:3267-72.

134.Lancranjan I, Bruns P, Grass P, et al. Sandostatin LAR: a promising therapeutic tool in the management of acromegalic patients. Metabolism 1996;45:67-71

135. Fløgstatd AK, Haise J, Bakke $S$, et al. Sandostatin LAR in acromegalic patients: long-term treatment for acromegaly, J Clin Endocrinol Metab 1997;82:23-8.

136.Turner HE, Vadivale A, Keenan J, Wass JAH. A comparison of lanreotide and octreotide LAR for treatment of acromegaly, Clin Endocrinol (Oxf) 1999;51:275-80.

137. Marzullo P, Baldelli R, Razzore P, Giaccio A, Gaia D, et al. Different efficacy of depot somatostatin analogs in therapy-resistant acromegaly. Proc $82^{\text {nd }}$ Annual Meeting of the Endocrine Society, Toronto, Canada, 2000 (Abstract Pl2167)

138. Pedroncelli AM, Montini M. Lancranjan IG. Two cases of acromegaly cured after medical treatment alone. Proc $82^{\text {nd }}$ Annual Meeting of the Endocrine Society, Toronto, Canada, 2000 (Abstract Pl-2182).

139. Thorner MO. Strasburger CJ, Wu Z, Straume M, et al. Growth hormone $(\mathrm{GH})$ receptor blockade with a PEG-modified $\mathrm{GH}$ (B2036-PEG) lowers serum insulin-like growth factor-l but does not acutely stimulate serum GH. J Clin Endocrinol Metab 1999:84:2098-103.

140.Trainer PJ, Drake WM, Katznelson L, Freda PU, et al. Treatment of acromegaly with the growth hormone-receptor antagonist pegvisomant. N Engl J Med 2000;342:11717.141. Bonert VSH. Growth hormone antagonist use in acromegaly. Proc $82^{\text {nd }}$ Annual Meeting of the Endocrine Socieły, Toronto, Canada, 2000 (Abstract P1-110).

142.Morrison KM, Bidlingmaier M, Wu Z, Christian J Strasburger CJ. Relationship of biochemical and clinical measures of disease activity in the treatment of acromegaly with the $\mathrm{GH}$ antagonist pegvisomant. Proc $\mathbf{8 2}^{\text {nd }}$ Annual Meeting of the Endocrine Society, Toronto, Canada, 2000 (Abstract PI1943).

143. Morgan B, Coy D. Taylor J, Murphy W. The influence of structure on subtype selectivity and efficacy at somatostatin receptors. J Endocrinol Invest 1997:20(suppl 7):5-7.

144.Lee EJ, Anderson LM, Thimmapaya B, Jameson JL, Targeted expression of toxlc genes receptor (SSTR) subtype-selective analogues differentially supress in vitro growth hormone and prolactin in human pituitary adenomas. Novel potential therapy for functional pituitary tumors. J Clin Invest 1997: 100:2386-92.

\section{Endereço para correspondência:}

Lucio Vilar

Rua Clóvis Silveira Barros, 84/1202 - Boa Vista

50.050-270 Recife, PE 